\title{
Buying on Weixin/WeChat: proposing a sociomaterial approach of platform studies
}

\section{Weiying Peng}

Hunan Normal University, China

\section{Wilfred Yang Wang}

University of Melbourne, Australia

Accepted on 1 October 2020 by Crosscurrent, Media Culture \& Society

Published on 4 November 2020 (online first)

\section{Abstract}

This article examines the social-commercial activity of microcommerce (wei shang), which has become popular on Weixin (WeChat), one of the most popular messenger applications/social app installed on smartphones in China. By drawing on the notion of platform affordances and data collected from mixed methods centred on the analysis of primary and secondary data, we contend that microcommerce embodies Weixin's structural (political economy) and cultural (social lives and norms) qualities in China. While microcommerce might have emerged from Weixin's ecosystem, which is defined by corporate interest and state's regulatory power, the practice of microcommerce is embedded within the traditional Chinese notion of shuren guanxi (familiar, non-stranger social relational) networks. This article puts forward a sociomaterial approach as a possible conceptual complement to the existing political economy approach of platform studies to call for greater attention to the intersection and interaction between the structural arrangements and social conditions of platform media.

\section{Keywords}

China, microcommerce, platform studies, socio-material, Weixin/WeChat 


\section{Introduction}

This article examines the online phenomenon of microcommerce (wei shang), a social-commercial activity that has become popular in China amid the popularization of Weixin/WeChat (Yang, Chen and Li, 2016). Unlike e-commerce, microcommerce transactions mainly occur between existing familiars (shu ren) in China (such as families, friends, and neighbors), contrasting with the conventional wisdom that the online sphere is a stranger-orientated network (Lai and Fung, 2019). Weixin has become a popular messenger and social media application (app) available on smartphone since its initial launch in 2011. By March 2020, Weixin has 1.2billion active monthly users in China and around the world under the brand 'WeChat' (Tencent, 2020). This article uses the term 'Weixin' to emphasize the indigeneity of the platform in terms of its usage and utilization. The study used a mixed-methods approach centered on the analysis of the primary and secondary sources. First, we examine interview data collected from twelve in-depth interviews with microcommerce buyers conducted between November 2018 and June 2019 in Changsha, one of the major urban metropolises in southern China, to understand the process and user experience of microcommerce. Further, we relied on the platform walkthrough method (Light, Burgess and Duguay, 2016) to reflect on those platform functions, structures, and boundaries emphasized by interview participants to ascertain the intersection between the technicality and sociality of Weixin. Third, we contextualized our study through analyzing industry reports and company financial statements about Weixin, Tencent and the larger digital economy in China.

Our inquiry has two objectives. The first is to identify and understand the cultural logic that underlines Weixin usage during microcommerce transactions. Drawing on the notion of (platform) affordances we pay attention to the platform's constant software updates and changes and, Tencent, Weixin's parent company's strategic repurposing in transforming the platform into an ecosystem of China's broader digital media landscape. Although existing literature has identified microcommerce as 'people-orientated' (Yang, Chen and Li, 2016), we argue that it is also 'endorsed' by 
Tencent's corporate strategy, which amplifies Weixin's structural (political economy) and cultural (social lives and norms) qualities. The second objective is to put forward a sociomaterial approach of platform media studies, which aims to understand those social and cultural conditions that the platform medium locates in. We argue that such conditions are co-constituted by two sets of relation: the relation between platform and users and, the relation between users. Specifically, we emphasize the interdependency and interactions between these two sets of relation in constituting the social experience with platform.

Being mindful of the limitation of our approach and the volatile nature of Weixin as any platform media (Weltevrede, 2016), this article offers a static snapshot of Weixin use within an evolving platform dynamic. The article aims to bring a sociomaterial perspective into the scholarly conversation of affordance, which has been dominated by the political economy approach on the one hand and, examples and case studies of US-based platform media on the other (Steinberg and Li, 2017). By emphasizing on the social reality of guanxi (social relational) network that Weixin operates in, we consider microcommerce on Weixin as a productive case study for testing and refining ideas about platform ecosystem outside the traditional context of platform media research and hence, to construct new analytical perspective and focus that might in turn, be useful to studies of platform media outside of China.

\section{Situating affordances in platform studies}

The platform theory that digital media researchers mainly draw on comes from two intellectual traditions. The first tradition originates from business and market research and views platform as a (free, neo-liberal) marketplace (Evan, 2011). Platform is deemed as the 'matchmaker' (Evan and Schmalensee, 2016) that facilitates the formation of 'platform-mediated networks' (McIntyre and Srinivasan, 2017) brings actors together and form new labour relations to co-create values (Lusch and Nambisan, 2015; Srnicek, 2017 ). The tradition of platform theory draws on those of computer science concepts, which perceive a platform as 'an operating system' that 
functions on programmed language and instructions (Bogost and Montfort, 2007; Galloway, 2006). The research tradition assumes a distinct form of division of labour that platform designer, developer, advertiser, and end-users (consumers) who are connected and interdependent with each other in co-creating the dynamics of digital platform. It is such a connection between different agents that have framed the conceptual theorization of affordances in platform studies.

As a conceptual notion, affordance was first coined by the ecological psychologist James Gibson's (2015), who studied the relationship between organisms and their living environments. He defines affordance as the 'opportunities for action' for organisms to respond to the structural arrangements of the environment they live in. Affordances are defined as the 'properties' of the relations between the environment and its observers (organisms) that guide the scope of actions (Stroffregen, 2003). The notion of 'property' has been developed further in Donald Norman's work on design thinking, which considers affordances as 'those fundamental properties that determine just how the thing could possibly be used' (Norman, 1988, p.9). He emphasizes on affordance's visibility to users that designer and/or developer should design in a way to ensure users can access and understand the way affordances operate, being used and perceived. William Gaver (1991) on the other hand, believes affordances are not exclusive to those visible properties but also the hidden feeling and experience produced through human interactions with the design (product, service, or platform). Instead of only focusing on those intended properties it is also important to learn those actual actions that embody the principles of affordances.

Social/digital media scholars agree that media technology's affordances have guided and constructed those high-level conditions of using and perceiving the media object (boyd, 2011; Helles, 2013) and low-level affordances that are embodied by technological feature and interface designs (Light, Burgess and Duguay, 2018). These two levels of affordance create protocols to scope the possible mode of platform usage (Galloway, 2006). As Langlois et al. (2009) put, online digital activity and 
practices are no simp human activity but need to be negotiated through software's architectural structure and design. Unlike Gibson's original examination affordance no longer takes place within a relatively stable and fixed 'ecological environment' but a constantly adapting and changing techno-social interface that is arbitrarily forged by computational changes and corporate strategic repurposing (Bucher and Helmond, 2018). In his study of Blued, the popular gay dating app in China, Wang (2020, p.317) notes how Blued users' in-app communication and practices with gay lived streamers are conducted "through the label/tags such as "muscles" and "little fresh meat" created by Blued'. The user culture is consistent with Blued's data structure and business model of monetizing the exchange between viewers and lived streamers.

Bloomfield, Latham and Vurdubakis (2010), however, cautious against overemphasizing on the technology's properties at the expense of the relational character of affordances. Using 'cooking with fire' as an illustration, the authors point out that fire is not by default for cooking, but human make fire 'cook' and manage it in a way to prevent undesirable outcomes such as housefire and bushfire. The meaning of affordances should not be reduced 'to their material constitution but are inextricably bound with specific, historically variable, ways of life' (p.428). This interpretation of affordance is a relational framework instead of a techno- or social-determinist approach because while human comes up with the idea of using fire to cook, our thinking and practices are still confined/responding to the available characters of fire. Our practices with fire are socially orientated and driven by materialistic needs. Focusing on the social orientations of affordances would allow a more indigenized understanding of how platforms operate across different social, cultural and political environments (Zhang, 2020).

Following the conceptual development of affordances, especially social/digital media affordances as highlighted above, this study is aimed to identify and examine both the visible and hidden, the structural and specific affordances of Weixin. We argue that microcommerce is both unintended but not unexpected within Weixin's ecosystem, a notion to be elaborated below. We consider microcommerce illustrates 
the sociomaterial characters of Weixin, which is made possible by the political economy of the platform and actualized by the indigenous social-cultural logic of guanxi network, the building-block of Chinese society.

\section{Microcommerce as part of Weixin's ecosystem}

As implied by the prefix 'micro-', microcommerce refers to those small-scale, often interpersonal, one-to-one direct transactions between the buyer and seller (ISC and Yuguang, 2016). According to a joint report prepared by the Internet Society of China $\left(\right.$ ISC) ${ }^{1}$ and Yiguang Analysys ${ }^{2}$, China's microcommerce development report 2015 (2016), microcommerce is a new form of digital business model that emphases on the relationship between individual Weixin users. Unlike conventional e-commerce that has built-in systems to monitor and review produce qualities and transaction experience, microcommerce relies on the interpersonal trusts and networks to forge and complete financial transactions, goods and services provision, and credibility/authenticity guarantee (ISC and Yuguang, 2016; Yang, Chen and Li, 2016). According to China Electronic Retails Association's Committee (AERAC) report (2019), by the end of 2018, microcommerce is an RMB ¥1.2trillion (USD\$170billion) worth industry and projected to reach RMB ¥1.9trillion (USD\$260billion) in 2020. There were more than 20million people engaged in the microcommerce 'workforce' (at various capacities) in 2017 (Yu and Cao, 2017).

The surge of microcommerce coincides with the popularization of mobile media and Weixin as the app supports microcommerce activities with its private and group chats, timeline (Moments, pengyou quan) and money-transfer functions (AERAC, 2019). Weixin is not just an instant messenger application installed on smartphone, but an infrastructure that encourages decentralized service model to recentralize the flow of data (Plantin and de Seta, 2019). As the marketing slogan on the simplified Chinese version of Weixin's official website (https://weixin.qq.com/) reads: Weixin, is a way of life (Weixin, shiyige shenghuo fangshi). 
The emergence of microcommerce is not strategically intended but not unexpected socially within the Weixin ecosystem. The notion of platform ecosystem refers to the assemblage of networks that centre around the corporate's economic and ideological interests, and to manage the processes of its development (van Dijck, Poell and de Waal, 2018). Platform tries to extend its indigenous functionalities into the larger platform media ecosystems by extending and expanding to accommodate new software developments and functions, and user-base service models (Bucher and Helmond, 2018). We use the term ecosystem rather than infrastructure (Plantin and de Seta, 2019) or operating system (Galloway, 2006) because it emphasizes the malleable nature of platform not only in terms of constant technical updates (Bucher and Helmond, 2018) and strategic corporate repurposing (Weltevrede, 2016), but also the dynamic mode of social engagement and material needs from using the platform. While living in a platform's ecosystem might allow users to utilize, imagine, and engage with the platform in a way they need to, the mode of engagement is, nonetheless, confined within the platform's technological affordances.

Tencent seems to focus on growing Weixin's users-base by making the platform as the centre of the larger digital media ecosystem in China. Tencent has done so in two ways. At the local platform level, Weixin has continuously been 'updating' to repurpose its functionality and service scope. It is a volatile medium that is highly adaptable to the broader social-economic transformations in China and indeed, around the world. With messaging as its central function, Weixin offers an integral structure that amalgamates diverse range of serves/functions (Jia and Winseck, 2018): private and group chat, timeline, games, public account and channel (gongzhong hao), miniprogram, as well as connecting to a range of external infrastructural service such as banking, charity and donation, stock exchange, and supporting public transportation transactions were gradually released over the years (see Table 1 in Plantin and de Seta, 2019, p.262). Weixin's technical updating follows what Nieborg and Helmond (2019) call as the 'outward extension' of smartphone app, which involves connecting its local, in-app functions (such as messaging) with services, software and even 
infrastructures outside the app's technical boundary (Zhang, 2020). It is only so, as Nieborg and Helmon (2019) writes, an app can become an ecosystem of social lives. It is indeed hard to live without Weixin in China. Important to note that some functions such as the 'drift bottle', which allowed users to find strangers in their surroundings, had disappeared as the State regulator accused the function promoted 'undesirable content' of pornography and solicit prostitutes (Borek, 2018). Weixin's technological repurposing is not entirely market-driven but also complying of the Chinese government's demand (Wang and Lobato, 2019)

At the corporate level, Tencent has been actively investing into e-commerce businesses with the most notable move of buying 15\% stake from JD.com in 2014 the second largest e-commerce marketplace in China (Meng, 2014). As a 'latecomer' to China's lucrative ecommerce market (Jia and Winseck, 2018), the investment was widely interpreted as a strategic move to take on Alibaba, who owns the largest B2C (business to customer) e-commerce platforms Taobao and Tmall (Meng, 2014). Tencent has since continued the investment trajectory by investing or entering a strategic partnership with local and global (e-)commerce and shared-economy services. $^{3}$ Tencent's investments aim to expand Weixin's ecosystem into the ecommerce market to re-configure the flow of user data from Weixin and other established e-commerce portals (Reuters, 2017). As Tencent's official corporate statements (Tencent, n.d.) indicates, Tencent's strategies with Weixin has been building it as a discursive ecosystem that accommodates new social and economic infrastructures to support major and mainstream transactions between individuals and institutions (the public, private and not-for-profit sectors) rather than merely a 'multisided marketplace' (Evans, 2011; Nieborg, 2015). Tencent's strategic platformization of national infrastructure has of course, received the endorsement from the State as Chinese governments rely on large internet corporations to develop and implement the digital transformation of its public services (Zhang, 2020).

\section{The sociality of Weixin}


A crucial aspect about microcommerce is the fact that it operates within Weixin's relatively close communicative network structure. Randomly searching for a (potential) contact is difficult if not impossible on Weixin. Adding a new contact requires either the person's Weixin username, phone number or QR code, which is a practice of mutual scanning that requires both parties' physical co-presence. This is despite the fact that users are required to verify their 'real name' (shi ming) by providing proper identification documents (such as ID cards or mobile phone number) in order to use any financial transaction related functions on Weixin (Summers 2019). Weixin's relatively enclosed platform network structure shows a highly personal and self-orientated communication networks that requires the user to actively engage in the building, maintenance, and mapping of their online networks. As Huang (2016) points out, microcommerce is essentially a $\mathrm{C} 2 \mathrm{C}$ (consumer-to-consumer) format that relies on the interpersonal relations and personal networks of the users (trader and sellers) to facilitate the financial transactions and the product/services provisions. Yin, Miao and Zhang (2015) emphases on the principal logics of social buildings and management amongst microcommerce merchants. In other words, the relationship between microcommerce seller and buyer is not mere transactional; the two ends of the transaction instead rely on a great deal of social capitals, personalities, and interpersonal/mutual trusts.

The historical original of microcommerce can be traced to daigou, the sociotechnical practice enabled by Weixin's affordances on a transnational scale. Daigou refers to the interpersonal trade practice 'of purchasing locally manufactured products overseas and reselling them to consumers in China' (Zhao, 2020, p.2). It is established that Chinese international students have been the main labour force in the daigou economy they are asked to bring commodities (such as vitamin supplements) back home by families and friends during their university breaks (Zhao, 2020; Martin, 2017). Many utilized their close personal networks to expand their 'customer base' since Weixin contacts are generally existing social networks such as families and friends. This observation adheres with established knowledge that Weixin is popular 
among Chinese family members who not only connect with each other online but also forms online family groups (Zhou and Gui, 2017).

While daigou literature have yet to draw on the notion of guanxi to reflect on Weixin's platform affordances, it is quite clear that the contact and social networks on Weixin are primarily shu ren (familiars)-driven and the platform affords guanxi network managements and building through its functionalities and communicative structures. Acknowledging the social and cultural complexity of the concept of guanxi, which has attracted vast interests from Chinese social/digital media researchers (Chen et.al. 2017; Luo and Yeh, 2012), an essential aspect of this notion is that guanxi networks must and can only exist between 'familiars' (Yang, 1994).

Familiarity underscores the cultural logics of Chinese society because it is the building block of social interactions between people (McDonald, 2018). Microcommerce activities have employed and amplified Weixin's affordances of different communicative practices that adhere to the notion of familiarity as described by our research participants. Choya (20s, female, recently graduated) for example, 'trusted' the first microcommerce seller she engaged with because the person was highly recommended by one of her best friends: 'my friend would not trick me into getting poor quality products or being cheated by the seller'. Choya's confidence was not only her personal relation with her friend but also the fact that she was connected with her friend on Weixin, which can be contacted 'instantly': 'if I have any question (about the seller), I can always ask my friend.' As Gaver (1996, p.114) argues, affordances do not just emerge through the relationship between individuals and the environments but also from the social interactions (and relations) between individuals' action within the environment. Techno-social elements work simultaneously to create these two sets of relations that support the Weixin ecosystem: the relations between Weixin and Choya (user) and Choya and her friend.

Guanxi is adjustable during one's life and it requires a great deal of effort and time to manage, maintain, and construct it (Fei, 1992; Luo and Yeh, 2012). Guanxi is an 'art', according to Mayfair Yang (1994), requiring one to navigate and negotiate 
across their different sets of personal and interpersonal networks. Weixin affords the performance of such art and it can be a delicate business. Navigating and managing guanxi via Weixin requires users to navigate the platform's technical infrastructures and functions and, social-material considerations. Wennie (30s, female, professional) for example, said she felt 'obligated' to buy something from families and friends who ran microcommerce business to show her support. The processes of placing order and transferring money (payment) on Weixin not only indicate the completion of the transaction but also symbolize the quality of Wennie's guanxi with her family and friends. Wennie's sense of reluctance also shows the material realities of Weixin use. Chengcheng (20s, female, professional) told us that when she first bought on Weixin, she spent few months observing someone's (a family friend) Weixin timeline before deciding to finally place an order (of baby products). Sammi (20s, female, professional) also said, she would only buy some 'small' or 'inexpensive' items (under RMB ¥100) from close family networks on Weixin because it would be awkward if things gone wrong: 'I can block a stranger (on Weixin) but I cannot block my families and close friends. Buying something small is like doing a favor for them but also protect myself (financially and socially).'

Weixin is not just for communication and nor is microcommerce merely about commercial transaction. While Weixin conditions the ways our research participants conduct themselves and imagine their guanxi networks, users also exploit Weixin's technical structures for their own social advantage and material needs. This userrepurposing practice is well illustrated in Fang's (30s, male, professional) case. Fang was a 'heavy user' of microcommerce and did most of his shopping on Weixin: from basic kitchenware to luxurious jewelry. While Fang bought from close friends and families who operated microcommerce on Weixin, he also made purchases from acquaintances who he did not personally know of. When asked why he trusted this kind of microcommerce sellers, Fang replied:

Although I do not personally know most of them (sellers) we are in the same industry professional Weixin group. There are few hundred people 
there (a private Weixin group can host up to 500 members) who all work in the same sector in the surrounding neighborhood communities. If anyone dares to cheat my money I will name and shame them in that Weixin group. It will be hugely embarrassing for the person. With that said, I also want to support those who are honest and working hard for lives. We work in the same industry and connected via the same Weixin group, so I kind of know them. I would rather let people who I know (of) make my money than giving money to total strangers like those on Taobao or JD.com.

Such a sense of remote guanxi connectedness and management are actualized through Fang's ability to access the Weixin group, where he could post and share textual and audiovisual materials. Further, Fang could see the full list of members in the group, which enabled his (perceived) power to 'name and shame' if things have gone wrong. A Weixin chat group also functioned like a conventional online community that forges members to develop a sense of closeness and connectedness with each other (joining a group with over 200 members needs to be invited by an existing group member) through the guanxi network structure in China.

\section{Towards a sociomaterial approach of platform studies}

Platform media research has become a productive field of inquiry that generates rich insights and knowledge about the social, economic and political aspects of a 'platformitized' world, a reference to the 'penetration of economic, governmental, and infrastructural extensions of digital platforms into the web and app ecosystems' (Nieborg and Poell, p. 2018). There are so far, two main streams of inquiry. The first stream critiques the corporate logics embedded in the process of platformization. Drawing on examples from western, mainly America-based platforms (Srnicek, 2016; Bucher and Helmond, 2018) and increasingly so, Chinese platforms (Jia and Winseck, 2018), scholars contend that platform companies' interests and power are extended and expanded into our social experience and ways of living (van Dijck, Poell and de 
Waal, 2014; Nieborg and Helmond, 2019). The second stream focuses on the state's governance and regulation of platform to reinforce the state's political power domestically and abroad (Glen, 2014; Nocetti, 2015). China has been frequently cited for its governments' active usage of platforms to provide infrastructural utility (Chen and Qiu, 2019), national imagination and ideological construction (Wang and Lobato, 2019), and economic transformation (Hong, 2017). Platform media have become the state's agent that supports its governing legitimacy and political survival (Zhang, 2020).

As van Dijck, Poell and de Waal (2014) propose, social experience with platform is produced through the constant tension and interactions between the state, market, and civil society, which are interconnected and interdependent through the complex assemblage of platform's network structures. These two streams are complementary to each other in seeking to explore a fundamental question about how platform governs and being governed (Gorwa, 2019). While these market and political-orientated approaches are crucial to understand the development trajectory of platform media on a macro-, structural level, they become somewhat abstract when evaluating individual practices and everyday lives. The political economy-heavy research tradition can take benefit from more nuanced understandings of the intersection between the sociality and materiality of platform media. We call for greater attention for developing a sociomaterial approach to study platform media both in and outside of China. By socio-, we refer to the structure, arrangement and operational logic of society. By -material, we refer to individuals' needs, expectations, and practices/actions in responding to the social arrangements in lives.

Guanxi network is not just a traditional culture but a way of being and doing in Chinese society. It has penetrated the online experience but also been reimagined and expressed through the platform qualities of Weixin. Microcommerce shows the 'renewal' of both the traditional concept (guanxi) and technological innovations (Weixin). This sociomaterial approach directs inquiry to 'go local and be specific' in examining social activity and online phenomenon to appreciate how platform media 
reproduce and are being reimagined through the realm of everyday lives. This approach is not to dismiss the ongoing significance of the political economy but an attempt to upscale platform media users' social and material needs to the center of critical inquiry. As affordances are the qualities that define the relational arrangement and structure between platform media and their users, then a sociomaterial approach can reinforce and operationalize inquiry into such a relational arrangement.

\section{Reference}

AERAC. (2019). 2018-2023 Global Social Retails Industries Study and Strategic Development Report (2018-2023 Quanqiu Shejiao Xin Lingshou Hangye Quanjing Diaocha yu Fazhan Zhanlv Yanjiu Baogao). China Electronic Retails Association's Committee (AERAC). Retrieved from http://www.wegoo.com.cn/art/index/96

Bogost, I., \& Montfort, N. (2009). New media as material constraint: an introduction to platform studies. HASTAC 2007 conference proceedings. Retrieved from https://www.hastac.org/electronic-techtonics-breakout-sessions/ian-bogost-andnick-montfort-new-media-material-constraint.

boyd danah (2011) Social network sites as networked publics: Affordances, dynamics, and implications. In: Papacharissi Z (ed.), A Networked self: identity, community, and culture on social network sites, New York: Routledge, pp. 39-58.

Bucher, T., \& Helmond, A. (2018). The Affordances of Social Media Platforms. In The SAGE Handbook of Social Media (pp. 233-253). London, Thousand Oaks, New Delhi, Singapore: SAGE Publications Ltd.

Bloomfield, B. P., Latham, Y., \& Vurdubakis, T. (2010). Bodies, Technologies and Action Possibilities. Sociology, 44(3), 415-433. doi:10.1177/0038038510362469

Borak, M. (2018, December 6). WeChat is suspending one of its popular features because people are using it to sell porn. Retrieved July 18, 2020, from https://www.techinasia.com/wechat-suspending-favorite-features-people-sell-porn 
Chen, J. Y., \& Qiu, J. L. (2019). Digital utility: Datafication, regulation, labor, and DiDi's platformization of urban transport in China. Chinese Journal of Communication, 12(3), 274-289. doi:10.1080/17544750.2019.1614964

Chen, L., Goh, C. F., Yifan, S., \& Rasli, A. (2017). Integrating guanxi into technology acceptance: An empirical investigation of WeChat. Telematics and Informatics, 34(7), 1125-1142. doi: 10.1016/j.tele.2017.05.003

Evans, D. S. (2011). Platform economics: Essays on multi-sided businesses. Lieu de publication non identifié: Competition Policy International.

Evans, D. S., \& Schmalensee, R. (2016). Matchmakers: The new economics of multisided platforms. Boston, MA: Harvard Business Review Press.

Fei, X. (1992). From the soil, the foundations of Chinese society. Berkeley, CA: University of California.

Galloway, A. (2006). Protocol how control exists after decentralization. Cambridge, MA: MIT Press.

Gaver, W. (1991, March 01). Technology affordances. Retrieved July 18, 2020, from https://dl.acm.org/doi/10.1145/108844.108856

Gaver WW (1996) Affordances for interaction: The social is material for design. Ecological Psychology 8(2): 111-129.

Gibson, J. J. (2015). The ecological approach to visual perception. New York, NY: Psychology Press.

Glen, C. M. (2014). Internet Governance: Territorializing Cyberspace? Politics \& Policy, 42(5), 635-657. doi:10.1111/polp.12093

Gorwa, R. (2019). What is platform governance. Information, Communication \& Society, 22(16), 854-871. doi:https://doi.org/10.1080/1369118X.2019.1573914

Helles, R. (2013). Mobile communication and intermediality. Mobile Media \& Communication, 1(1), 14-19. doi:10.1177/2050157912459496

Hong, Y. (2017). Networking China: The digital transformation of the Chinese economy. Urbana, Chicago, and Springfield: University of Illinois Press. 
Huang, L. (2016). zAnalysing trusts in microcommerce (Weishang xinren fenxi).

Business (Shang), 25. Retrieved from

http://mall.cnki.net/magazine/Article/SHNG201625178.htm

ISA, \& Yiguan Analysys. (2015). China's microcommerce development report 2015 (zhongguo weishang fazhan zhuangkuang yanjiu baogao 2015) . Internet Society of China (ISC) and Yiguan Analysys. Retrieved from https://wenku.baidu.com/view/2618995ab14e852459fb575c.html

Jia, L., \& Winseck, D. (2018). The political economy of Chinese internet companies: Financialization, concentration, and capitalization. International Communication Gazette, 80(1), 30-59. doi:10.1177/1748048517742783

Lai, G., \& Fung, K. Y. (2019). From online strangers to offline friends: A qualitative study of video game players in Hong Kong. Media, Culture \& Society, 42(4), 483501. doi:10.1177/0163443719853505

Langlois, G. (2016). Meaning in the age of social media. Place of publication not identified: Palgrave Macmillan.

Light, B., Burgess, J., \& Duguay, S. (2016). The walkthrough method: An approach to the study of apps. New Media \& Society, 20(3), 881-900. doi:10.1177/1461444816675438

Luo, J.-D., \& Yeh, Y.-C. (2012). Neither collectivism nor individualism: Trust in the Chinese guanxi circle. Journal of Trust Research, 2(1), 53-70. doi: $10.1080 / 21515581.2012 .660355$

Lusch, R. F., \& Nambisan, S. (2015). Service innovation: A service-dominant logic perspective. MIS Quarterly, 39(1), 155-175.

Martin, F. (2017). Rethinking network capital: hospitality work and parallel trading among Chinese students in Melbourne. Mobilities, 12(6), 890-907. doi: $10.1080 / 17450101.2016 .1268460$

McDonald, T. (2018). Strangership and Social Media: Moral Imaginaries of Gendered Strangers in Rural China. American Anthropologist. 
McIntyre, D. P., \& Srinivasan, A. (2017). Networks, platforms, and strategy: Emerging views and next steps. Strategic Management Journal, 38(1), 141-160.

Meng, J. (2014, March 10). Tencent to take 15\% stake in JD.com. Retrieved July 18, 2020, from http://www.chinadaily.com.cn/business/tech/201403/10/content_17335176.htm

Nieborg, D. B., \& Helmond, A. (2018). The political economy of Facebook's platformization in the mobile ecosystem: Facebook Messenger as a platform instance. Media, Culture \& Society, 41(2), 196-218. doi:10.1177/0163443718818384

Nieborg, D. B., \& Poell, T. (2018). The platformization of cultural production: Theorizing the contingent cultural commodity. New Media \& Society, 20(11), 4275-4292. doi:10.1177/1461444818769694

Nocetti, J. (2015). Contest and conquest: Russia and global internet governance. International Affairs, 91(1), 111-130. doi:10.1111/1468-2346.12189

Norman, D. A. (1988). The psychology of everyday things. New York: Basic Books.

Plantin, J., \& Seta, G. D. (2019). WeChat as infrastructure: The techno-nationalist shaping of Chinese digital platforms. Chinese Journal of Communication, 12(3), 257-273. doi:10.1080/17544750.2019.1572633

Reuters. (2017, December 18). China's Tencent, JD.com invest $\$ 863 \mathrm{mln}$ in online retailer Vipshop. Retrieved July 18, 2020, from https://www.reuters.com/article/tencent-holdings-jdcom-vipshop-hldg/chinastencent-jd-com-invest-863-mln-in-online-retailer-vipshop-idUSL4N1OI1H6

Srnicek, N. (2017). Platform capitalism. Cambridge, UK: Polity.

Steinberg, M., \& Li, J. (2017). Introduction: Regional Platforms. Asiascape: Digital Asia, 4(3), 173-183. doi:10.1163/22142312-12340076

Stoffregen, T. A. (2018). Affordances as Properties of the Animal-Environment System. How Shall Affordances Be Refined? Four Perspectives, 115-134. doi:10.4324/9780203726655-2 
Summers, J. (2019, May 31). How to Set Up WeChat Wallet: Guide for China Expats and Travelers. Retrieved June 16, 2020, from https://www.travelchinacheaper.com/using-wechat-wallet

Tencent. (n.d.). Tencent - Business. Retrieved June 8, 2020, from https://www.tencent.com/zh-cn/business.html

Tencent Global. (2020, May 13). Tencent Announces 2020 First Quarter Results. Retrieved June 8, 2020, from https://mp.weixin.qq.com/s/IH09J0CGOJqaYHFWXC4fNw

van Dijck, J., Poell, T., \& Waal, M. D. (2018). The platform society: Public values in a connective world. Oxford: Oxford University Press.

Wang, S. (2020). Chinese affective platform economies: Dating, live streaming, and performative labor on Blued. Media, Culture \& Society, 42(4), 502-520. doi:10.1177/0163443719867283

Wang, W. Y., \& Lobato, R. (2019). Chinese video streaming services in the context of global platform studies. Chinese Journal of Communication, 12(3), 356-371. doi:10.1080/17544750.2019.1584119

Weltevrede, E. (2016). Repurposing digital methods: The research affordances of platforms and engines (Master's thesis, Proefschrift Universiteit van Amsterdam, 2016). Amsterdam.

Yang, M. M.-hui. (1994). Gifts, Favors, and Banquets The Art of Social Relationships in China. Ithaca and London: Cornell University Press.

Yang, S., Chen, S., \& Li, B. (2016). The Role of Business and Friendships on WeChat Business: An Emerging Business Model in China. Journal of Global Marketing, 29(4), 174-187. doi:10.1080/08911762.2016.1184363

Yin, Y., Miao, W., \& Zhang, S. (2015). A study of the trust mechanism in microcommerce (weishang de xinren jizhe yanjiu). Modern Business Magazine (Xiandai Shangye), 2. Retrieved from http://www.xdsyzzs.com/shichangyingxiao/881.html 
Yu, L., \& Cao, Y. (2017). China's microcommerce industry development report 2017 (2017 zhongguo weishang hangye fazhan baogao). Internet Society of China (ISC). Retrieved from https://tech.huanqiu.com/article/9CaKrnK437B

Zhang, Z. (2020). Infrastructuralization of Tik Tok: Transformation, power relationships, and platformization of video entertainment in China. Media, Culture \& Society, 016344372093945. doi:10.1177/0163443720939452

Zhao, X. (2020). Digital labour in transnational mobility: Chinese international students' online boundary work in daigou. New Media \& Society.

Zhou, B., \& Gui, S. (2017). WeChat and Distant Family Intergenerational Communication in China: A Study of Online Content Sharing on WeChat. Communication, Culture and Change in Asia New Media and Chinese Society, 185-206. doi: 10.1007/978-981-10-6710-5_11.

\section{Notes}

1 One of the most established non-government organization consists of private companies and research institutes in the internet industry in China (https://www.isc.org.cn/english/)

2 One of the largest technology market research firms, specialize in big data analytic in China.

3 Tencent invested into Vipshop, a high-end fashion e-commerce platform in 2017 and formed joint business partnership with L'Oreal to launch new e-marketing solutions (2017) 


\section{University Library}

\section{- M M N E R VA A gateway to Melbourne's research publications}

Minerva Access is the Institutional Repository of The University of Melbourne

Author/s:

Peng, W;Wang, WY

Title:

Buying on Weixin/WeChat: Proposing a sociomaterial approach of platform studies

Date:

2020-11-04

Citation:

Peng, W. \& Wang, W. Y. (2020). Buying on Weixin/WeChat: Proposing a sociomaterial approach of platform studies. MEDIA CULTURE \& SOCIETY, 43 (5), pp.945-956. https:// doi.org/10.1177/0163443720968460.

Persistent Link:

http://hdl.handle.net/11343/249513 